\title{
ANTICANCER ACTIVITY OF PLANT PROTEIN AGAINST DALTON'S LYMPHOMA ASCITES TUMOR CELL LINES
}

\begin{abstract}
SRILATHA $M^{1 *}$, SANTHI R ${ }^{2}$, ANNAPURANI $S^{2}$
${ }^{1}$ Department of Biotechnology, Avinashilingam Institute for Home Science and Higher Education for Women, Coimbatore - 641043, Tamil Nadu, India. ${ }^{2}$ Department of Biochemistry, Biotechnology and Bioinformatics, Avinashilingam Institute for Home Science and Higher Education for Women, Coimbatore - 641 043, Tamil Nadu, India. Email: sripathy1331@gmail.com
\end{abstract}

Received: 24 August 2016, Revised and Accepted: 22 September 2016

\section{ABSTRACT}

Objective: Tabernaemontana divaricata (Td) is commonly used plants for the treatment of inflammatory, anticancer, and diabetics. The main objective of this study is to assess the antitumor and antioxidant activity of Td in mice model.

Methods: Antitumor activity of TdPf extract (52 $\mu \mathrm{g} / \mathrm{ml})$ is evaluated against Dalton's lymphoma ascites (DLA) tumor mice. After 24 hrs of tumor inoculation, the extract is administered daily for 15 and 60 days. After administration of the lost dose followed by 18 hrs fasting, mice are sacrificed for observation of antitumor activity. Antitumor activity is assessed by monitoring the liver marker enzyme, lipid peroxidation effect on antioxidant enzyme levels, and histopathological evidence.

Results: The results showed that the protein extract of Td animals restored the antioxidant enzymes when compared to the mice of the DLA control group.

Conclusion: The findings indicate that the extract of plant protein has antitumor activity by preventing the lipid peroxidation and thereby promoting the antioxidant systems in DLA induced mice. And hence, it is evident that these extract could be a natural anticancer agent for the human health.

Keywords: Dalton's lymphoma ascites, Antitumor, Tabernaemontana divaricata, Lipid peroxidation antioxidant.

(C) 2017 The Authors. Published by Innovare Academic Sciences Pvt Ltd. This is an open access article under the CC BY license (http://creativecommons. org/licenses/by/4. 0/) DOI: http://dx.doi.org/10.22159/ajpcr.2017.v10i1.14878

\section{INTRODUCTION}

Cancer is a major health hazard in the world and claims over six million lies every year (Abdullaev, 2001). Cancer, a term comprising over 100 types of malignancy, is one of the major burdens of chronic disease in the world. It is very difficult to cure this disease pathogenesis due to its multifactorial etiology. Early in the $20^{\text {th }}$ century, only cancers small and localized enough to be completely removed by surgery were curable. Later, radiation was used after surgery to control small tumor growths that were not surgically removed. Finally, chemotherapy was added to destroy small tumor growths that had spread beyond the reach of the surgeon and radiotherapist [1,2]. Plant derived substances have recently become of great interest in owing to their versatile applications. Medicinal plants are the richest bioresources of drugs of traditional systems of medicine, nutraceuticals, food supplements, folk medicines, pharmaceuticals intermediates, and chemical entities for synthetic drugs [3]. The medicinal value of plants lies in some chemical substances that produce a definite physiological action on the human body. Many of the indigenous medicinal plants are used as spices [4]. With the aim of searching novel compounds without undesirable side effects, we focused on natural medicines. Plants are reported to have a long history in the treatment of cancer [5]. The use of plants and plant-based products for cancer treatment is rapidly growing in medical practices [6].

Scientific advancements have led to the exploration of many such plants chemically for its constituents and their impact in treating several types of diseases. As little attention has been devoted to understand the functional role of ethno-medicinally important plant proteins in relation to its therapeutic use and considering the potential advantage of using plant proteins as drugs (due to nontoxic nature), a through scientific research is attempted. Proteome analysis deals with determination of biological roles and functions of identified proteins [7].
This led us to choose the medicinal plant named as Tabernaemontana divaricata (Td) (Tamil-Nandhiyar vattam). This plant has been used in the traditional medicine of the Indian Ayurvedic system belonging to Apocynaceae family which is a small shrub, about $54 \mathrm{~cm}$ high, with large shiny leaves, crepe jasmine flowers, and appearing sporadically all year. It is a rich source of secondary metabolites with various pharmacological properties. It has been used in the folk medicine for anti-infection, antitumor, and antioxidative effect and the effect in neuronal activity (Pratchayasakul et al., 2008) [8]. The objective of this study is to evaluate the antitumor activity of protein extract being reported to validate the traditional use of the crude drug through in vivo evaluation. Our results suggest that whole plant extracts are promising anticancer agent.

\section{METHODS}

\section{Collection and authentication of plant}

The fresh leaves of Td (Apocynaceae) were collected from Coimbatore district, India. Taxonomic authentication was done by Dr.G.V.S. Murthy Taxonomist, TNAU, Coimbatore, Tamil Nadu, India, and the authentication number BSI/SRC/5/23/2015/Tech/2083.

\section{Preparation of protein extract of Td leaf (TdPf)}

Protein was extracted by recrystallization of ammonium sulfate. $20 \%$ fresh leaves of Td were taken and homogenized with phosphate-buffered saline buffer $\mathrm{pH} 7.2$ and were centrifuged for $5000 \mathrm{rpm}$ for 10 minutes. Pellets were discarded and supernatant was saved. To the supernatant add $10-100 \%$ ammonium sulfate and was centrifuged at 10,000 rpm, $4^{\circ} \mathrm{C}$ for 10 minutes. The supernatant was discarded and the pellet was suspended with dialysis membrane for salting out. The crude extract was kept at $-20^{\circ} \mathrm{C}$. 
Chemicals

The chemicals and solvents used in the study were of the highest purity and analytical reagents grade. The chemicals were purchased from SD Fine Chem., Himedia and Sigma, India.

\section{Experimental animals}

About 70-day-old Swiss albino mice weighing $20 \pm 2 \mathrm{~g}$ were used for this study. The mice were procured from the Amala cancer Research Institute Kerala, India. The mice were divided into five groups (six mice per group) and maintained in polyacrylic cages at a temperature of $25 \pm 2^{\circ} \mathrm{C}$, suitable humidity, dark/light cycle, with feed and water (ad-libitum). The mice were acclimatized to laboratory conditions for 7 days before the commencement of the experiment. The animal care and handling was done according to the regulations of Council Directive CPCSEA No: (IAEC.2015.BT:04) about good laboratory practice on animal experimentation. All animal experiments were performed in the laboratory according to the ethical guidelines suggested by the International Animal Ethics Committee.

\section{Induction of lymphoma}

Dalton's lymphoma ascites (DLA) cells were obtained from Amala Cancer Research Institute, Kerala, India. The cells were maintained in vivo in Swiss albino mice by intraperitoneal transplantation of $1 \times 10^{6}$ cells/mouse. The DLA cells aspirated from the peritoneal cavity of the mice were washed with saline and given intraperitoneally to the experimental animals to develop ascitic tumors.

\section{Experimental design}

A total of 30 Swiss albino mice were divided into five groups $(n=6)$ and given food and water ad libitum. The vehicle and extract were administrated intraperitoneal for 15 and 30 days. Group A served as control group; Group B mice induced with paraffin; Group C mice induced with silymarin, Group D mice induced with TdPf alone with effective concentration $50 \%$ value of $52 \mu \mathrm{g} / \mathrm{kg}$ body weight from the next day of induction for 15 and 60 days; Group E mice intraperitoneal administered with DLA and protein fraction of Td for 15 and 60 days. Group F received DLA cancer cells alone (i.e.,) $10^{-6}$ cells $/ \mathrm{ml}$. After the treatment period, six animals of each group were sacrificed by cervical dislocation to measure antitumor activity. The blood was collected from the animals by heart puncture. From the collected blood sample, the serum was separated and the liver marker enzyme was estimated such as serum glutamic-oxaloacetic transaminase (SGOT), serum glutamyl pyruvate transaminase (SGPT), and alkaline phosphatase (ALP). Similarly, the liver sample was used to estimate the enzymic and nonenzymic antioxidant assay and also lipid peroxidation was analyzed.

\section{Preparation of tissue homogenate}

The liver was removed quickly and washed in ice cold isotonic saline. The tissue was homogenized in $0.1 \mathrm{M}$ Tris- $\mathrm{HCl}$ buffer of $\mathrm{pH} 7.4$ at $4^{\circ} \mathrm{C}$ in a potter homogenizer, at $6000 \mathrm{rpm}$ for 5 minutes. The filtrate was used for further estimations.

\section{Analytical methods}

\section{Serum biochemical parameters}

Estimation of the liver marker enzymes such as aspartate transaminase (SGOT), alanine transaminase (SGPT), and ALP was carried out in the serum samples using Standard Kit method (Genei diagnostics).

\section{Estimation of lipid peroxidation}

Lipid peroxidation was measured by the thiobarbituric acid (TBA) reaction method. In brief, samples were mixed with TBA reagent consisting of $0.375 \%$ TBA and $15 \%$ trichloroacetic acid in $0.25 \mathrm{~N}$ hydrochloric acid. The reaction mixtures were placed in a boiling water bath for 30 minutes and centrifuged at $1800 \mathrm{~g}$ for 5 minutes. The absorbance of the supernatant was measured at $535 \mathrm{~nm}$. Malondialdehyde, a measure of lipid peroxidation, was calculated using an extinction coefficient of $1.56 \times 10^{5} / \mathrm{M} \mathrm{cm}$. The results were expressed as $\mu \mathrm{M} / \mathrm{mg}$ protein.

\section{Antioxidant assays}

The liver homogenate was used to analyze the enzymatic antioxidant activities by superoxide dismutase (SOD), catalase (CAT), glutathione (GSH) peroxidase (GPx), and nonenzymatic antioxidants such as vitamin $\mathrm{A}$, vitamin $\mathrm{E}$, and reduced GSH were evaluated in the liver tissue homogenate using Standard Kit methods.

\section{Histopathological study}

The liver tissue samples collected were fixed in $10 \%$ formalin solution. After fixation, the tissues were embedded in paraffin and sections cut at $5 \mu \mathrm{m}$ to later be stained with hematoxylin and eosin. The sections were then examined under light microscope and photographed (Standish et al., 2006).

\section{Statistical analysis}

The results obtained were reported as mean \pm standard deviation. One-way and two-way analysis of variance was performed to analyze statistically significance of the data using Agres Statistical Package.

\section{RESULTS}

\section{Estimation of liver marker enzymes in serum samples}

Graph 1a-c shows the activities of marker enzymes in control and lymphoma bearing animals, respectively. In lymphoma bearing animals, the activities of the aspartate aminotransferase (AST) and alanine aminotransferase (ALT) were significantly (69.40 \pm 2.48 ; $82.87 \pm 4.98$ ) increased, whereas ALP were found to be significantly $(56.51 \pm 3.81 ; 40.02 \pm 1.28 ; 8.97 \pm 1.33)$ increased when compared to the control mice $(p<0.05)$. All the marker enzymes were found to be significantly increased in the serum of tumor bearing animals when compared to normal control mice. On TdPf treatment, the activities of all these enzymes were significantly brought back to near normal levels.

\section{Estimation of lipid peroxidation}

This study shows that a significant increase in lipid peroxidation (Graph 2) was observed in DLA induced mice.

\section{Estimation of antioxidant activity} Enzymatic antioxidant

DLA cells induced mice showed a significant $(\mathrm{p}<0.05)$ decreased levels of SOD $(0.83 \pm 0.03)$, CAT $(1.93 \pm 0.03)$, and GPx $(0.99 \pm 0.01)$. The treatment of TdPf alone at $5.2 \mu \mathrm{g} / \mathrm{kg}$ body weight showed a significant increased levels of SOD $(1.74 \pm 0.46)$, CAT $(1.94 \pm 0.03)$, and GPx $(0.99 \pm 0.01)$ when compared to the normal mice group and also highly significant in 60 days of treated animals $(\mathrm{p}<0.05)$ (Table 1).

\section{Estimation of nonenzymic antioxidants}

Table 2 exhibits the levels of nonenzymatic antioxidants in the liver of control and experimental animals. From the Table 2, it is found that the level of vitamin A, vitamin E, and GSH was significantly reverted back to near normal level when treated with the plant extracts when compared to Group III treated (standard antioxidant).

Histopathological observations in the liver of TdPf treated mice were comparable to that of controls and silymarin without any structural changes in the liver morphology.

Plate 1a-j indicates the histopathological observation of DLA bearing mice, (a) Untreated; (b) paraffin oil 15 days observation; (c) silymarin (standard drug); (d) protein extract (TdPf); (e) protein extract + DLA; (f) paraffin oil 60 days observation; (g) silymarin 60 days observation; (h) plant extract 60 days; (i) plant extract + DLA 60 days; (j) DLA 15 days observation.

Hepatic cells of DLA induced mice showed large confluent areas of hepatocellular necrosis with peripheral rim of surviving cells with focal steatosis and ballon degeneration. This could be due to the formation of highly reactive radicals because of oxidative threat caused by DLA. 


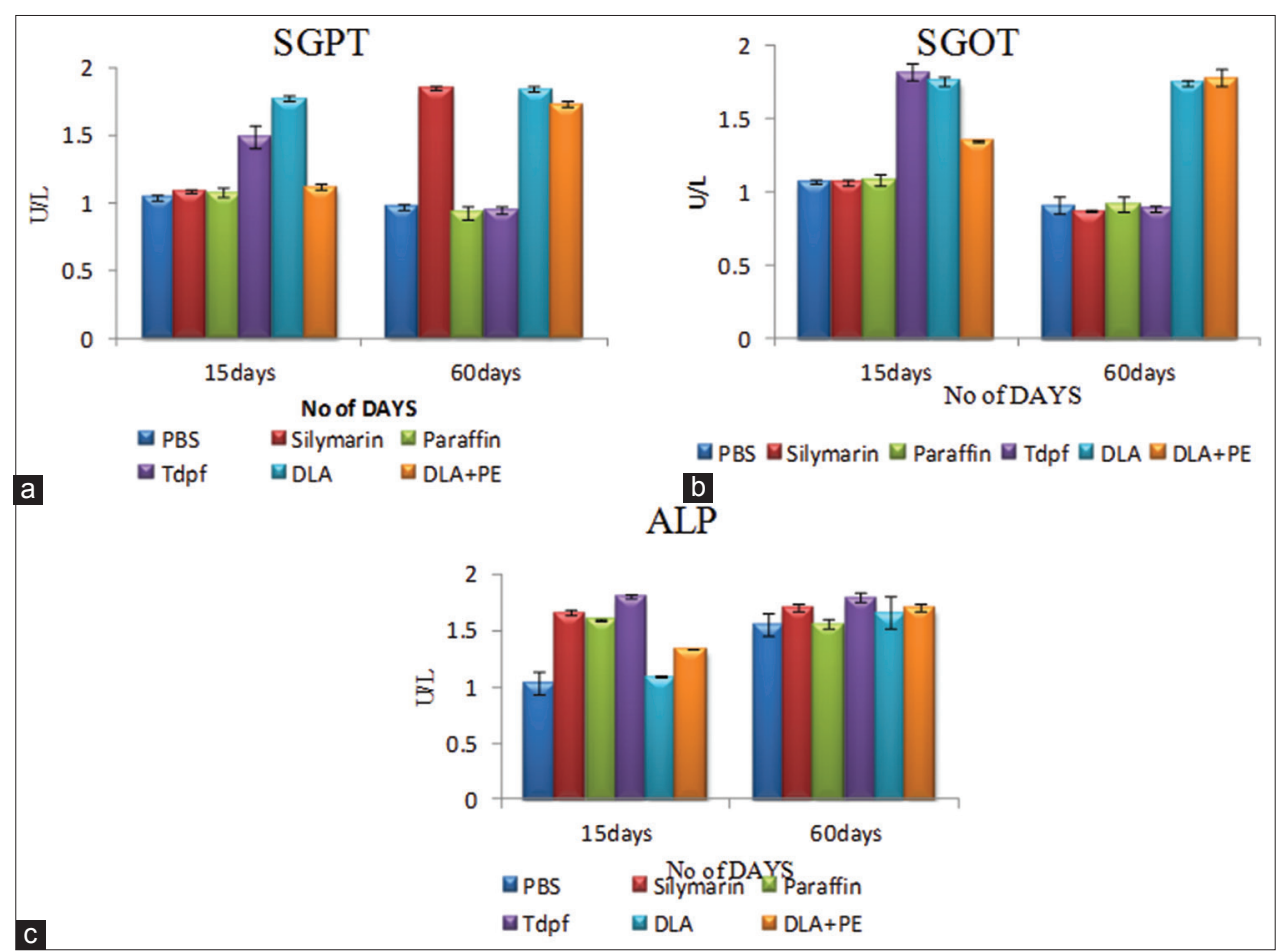

Graph 1: (a) Activities of liver marker enzymes in serum of treated mice (serum glutamic pyruvate transaminase), (b) activities of liver marker enzymes in serum of treated mice (serum glutamic-oxaloacetic transaminase), (c) activities of liver marker enzymes in serum of treated mice (alkaline phosphatase). The values mean \pm standard deviation of six animals



Graph 2: Changes in the level of lipid peroxidation

However, the treatment with TdPf exerted a significant inhibition of metastasis in the liver indicating their antimetastatic activity which could be comparable to that of silymarin, the standard drug used for comparison. However, TdPf was found less efficient in preventing metastasis at abdominal muscle when compared to silymarin (Plate 1c, d, h and i).

\section{DISCUSSION}

Many natural products have served as anticancer agents in the treatment and also as lead compounds for further research. Many plants are used to treat tumors in the Indian traditional system of medicine, but most of the plants have not been scientifically evaluated (Pushpangadan and Subramonian, 1998). Hence, enormous scope exists for identifying potent anticancer plants. Based on our earlier studies, this work was aimed to evaluate the TdPf for in vivo antitumor properties. ALT catalyses the conversion of alanine to pyruvate and glutamate and is released in a similar manner. Elevated levels of serum enzymes are indicative of cellular leakage and loss of functional integrity of cell membrane in the liver [9]. A similar significant decrease in AST, ALT, and ALP was observed by Santhi and Annapoorani [10] by the administration of silymarin to carbon tetrachloride $\left(\mathrm{CCl}_{4}\right)$ induced hepatotoxicity in mice. Heba et al. [11] also reported that rats fed with powder of Ziziphus spina-christi fruit decrease the activities of AST, ALT, and ALP in $\mathrm{CCl}_{4}$ induced rats in a dose-dependent manner. A similar significant increase in the activity of AST in the serum of ELA induced mice was reported by Nalini et al. [12].

Elevated lipid peroxidation and a poor antioxidant system have been reported in cancer patients. Altered activities of enzymatic antioxidants are reported during carcinogenesis or after tumor formation. Hence, the elevated lipid peroxidation in the circulation of cancer animals is due to a poor antioxidant defense mechanism [13]. A decrease in SOD and CAT activities described in tumors is regarded as a marker of malignant transformation. Lowered activities of SOD and CAT were reported in several cancers [14].

Excessive generation of reactive oxygen species has been considered as hallmark in several cancers, including Dalton's ascitic tumor model [15]. Antioxidant enzymes that scavenge intermediates of oxygen reduction provide a primary defense against free radicals in situ. It is well known that SOD, CAT, and GPx also play important roles as protective enzymes against LPO in tissues [16]. Several investigators reported that reduced activities of SOD, CAT, and GPx in tumor-bearing animals may be due to a down-regulation of SOD and CAT genes induced by certain hormonal factors or ROS themselves (Quan et al., 2011).

Antioxidants are important substances with the ability to protect the body from damage caused by free radical-induced oxidative stress. A variety of free radical scavenging antioxidants exists within the body. Vitamin A has been associated with a decreased risk of human cancer and has protective effects in animal models of carcinogenesis. Vitamin A is known to be an important natural antioxidant capable of counteracting oxygen free radicals and exerting a protective antioxidant 
Table 1: Effect of pretreatment with crude protein extract from $T$. divaricata leaves on activities of enzymatic antioxidants in liver of male albino mice

\begin{tabular}{|c|c|c|c|c|c|c|}
\hline \multirow[t]{2}{*}{ Groups } & \multicolumn{2}{|c|}{ SOD (U/mg protein) ${ }^{a}$} & \multicolumn{2}{|c|}{ CAT $(\mathrm{U} / \mathrm{mg} \text { protein })^{\mathrm{b}}$} & \multicolumn{2}{|c|}{ GPx (U/mg protein) ${ }^{c}$} \\
\hline & 15 days & 60 days & 15 days & 60 days & 15 days & 60 days \\
\hline PBS control & $0.83 \pm 0.03$ & $1.44 \pm 0.09$ & $1.93 \pm 0.03$ & $2.52 \pm 0.15$ & $0.99 \pm 0.01$ & $0.51 \pm 0.06$ \\
\hline Paraffin control & $1.85 \pm 0.03$ & $0.37 \pm 0.03$ & $1.94 \pm 0.02$ & $2.59 \pm 0.22$ & $0.93 \pm 0.04$ & $1.37 \pm 0.21$ \\
\hline Silymarin & $1.90 \pm 0.05$ & $0.39 \pm 0.02$ & $1.26 \pm 0.10$ & $2.81 \pm 0.02$ & $0.90 \pm 0.02$ & $0.46 \pm 0.03$ \\
\hline TdPf & $1.74 \pm 0.46$ & $0.75 \pm 0.06$ & $1.94 \pm 0.03$ & $2.57 \pm 0.21$ & $0.99 \pm 0.01$ & $0.46 \pm 0.03$ \\
\hline TdPf+DLA & $1.61 \pm 0.04$ & $2.16 \pm 0.11$ & $1.06 \pm 0.01$ & $2.47 \pm 0.04$ & $0.87 \pm 0.20$ & $2.27 \pm 0.18$ \\
\hline DLA & $1.61 \pm 0.40$ & $2.26 \pm 0.02$ & $1.68 \pm 0.08$ & $2.26 \pm 0.03$ & $1.76 \pm 0.04$ & $2.29 \pm 0.02$ \\
\hline
\end{tabular}

The values mean \pm SD of six animals; a Amount of enzyme that gives $50 \%$ inhibition of the extent of NBT reduction for SOD, bamount of enzyme required to decrease the absorbance by 0.05 units at $240 \mathrm{~nm}$ for CAT and 'microgram of GSH utilized/minute. A significant at p<0.05 as compared to control group. SD: Standard deviation, SOD: Superoxide dismutase, CAT: Catalase, GPx: Glutathione peroxidase, DLA: Dalton's lymphoma ascites, TdPf: Tabernaemontana divaricata

Table 2: Effect of pretreatment with crude protein from T. divaricata leaves on activities of nonenzymatic antioxidants parameters in liver of male albino mice

\begin{tabular}{|c|c|c|c|c|c|c|}
\hline \multirow[t]{2}{*}{ Groups } & \multicolumn{2}{|c|}{ Vitamin A ( $\mu \mathrm{g} / \mathrm{g}$ tissue) } & \multicolumn{2}{|c|}{ Vitamin E ( $\mu \mathrm{g} / \mathrm{g}$ tissue $)$} & \multicolumn{2}{|c|}{ GSH (n moles/g tissue) } \\
\hline & 15 days & 60 days & 15 days & 60 days & 15 days & 60 days \\
\hline PBS control & $1.81 \pm 0.01$ & $1.90 \pm 0.04$ & $1.81 \pm 0.01$ & $1.43 \pm 0.04$ & $1.71 \pm 0.03$ & $1.43 \pm 0.08$ \\
\hline Silymarin & $0.80 \pm 0.04$ & $2.05 \pm 0.08$ & $0.83 \pm 0.04$ & $2.14 \pm 0.04$ & $0.89 \pm 0.03$ & $2.23 \pm 0.04$ \\
\hline TdPf & $2.32 \pm 0.04$ & $2.17 \pm 0.03$ & $2.40 \pm 0.12$ & $2.19 \pm 0.04$ & $2.43 \pm 0.04$ & $2.20 \pm 0.04$ \\
\hline TdPf+DLA & $1.70 \pm 0.04$ & $2.05 \pm 0.04$ & $1.60 \pm 0.04$ & $2.14 \pm 0.04$ & $1.79 \pm 0.04$ & $2.16 \pm 0.04$ \\
\hline DLA & $1.64 \pm 0.04$ & $1.67 \pm 0.04$ & 1.540 .04 & $1.70 \pm 0.04$ & $1.61 \pm 0.08$ & $1.74 \pm 0.04$ \\
\hline
\end{tabular}

The values mean \pm SD of six animals; A significant at $\mathrm{p}<0.05$ as compared to control group. Histopathological examination. PBS: Phosphate buffered saline, DLA: Dalton's lymphoma ascites, TdPf: Tabernaemontana divaricata

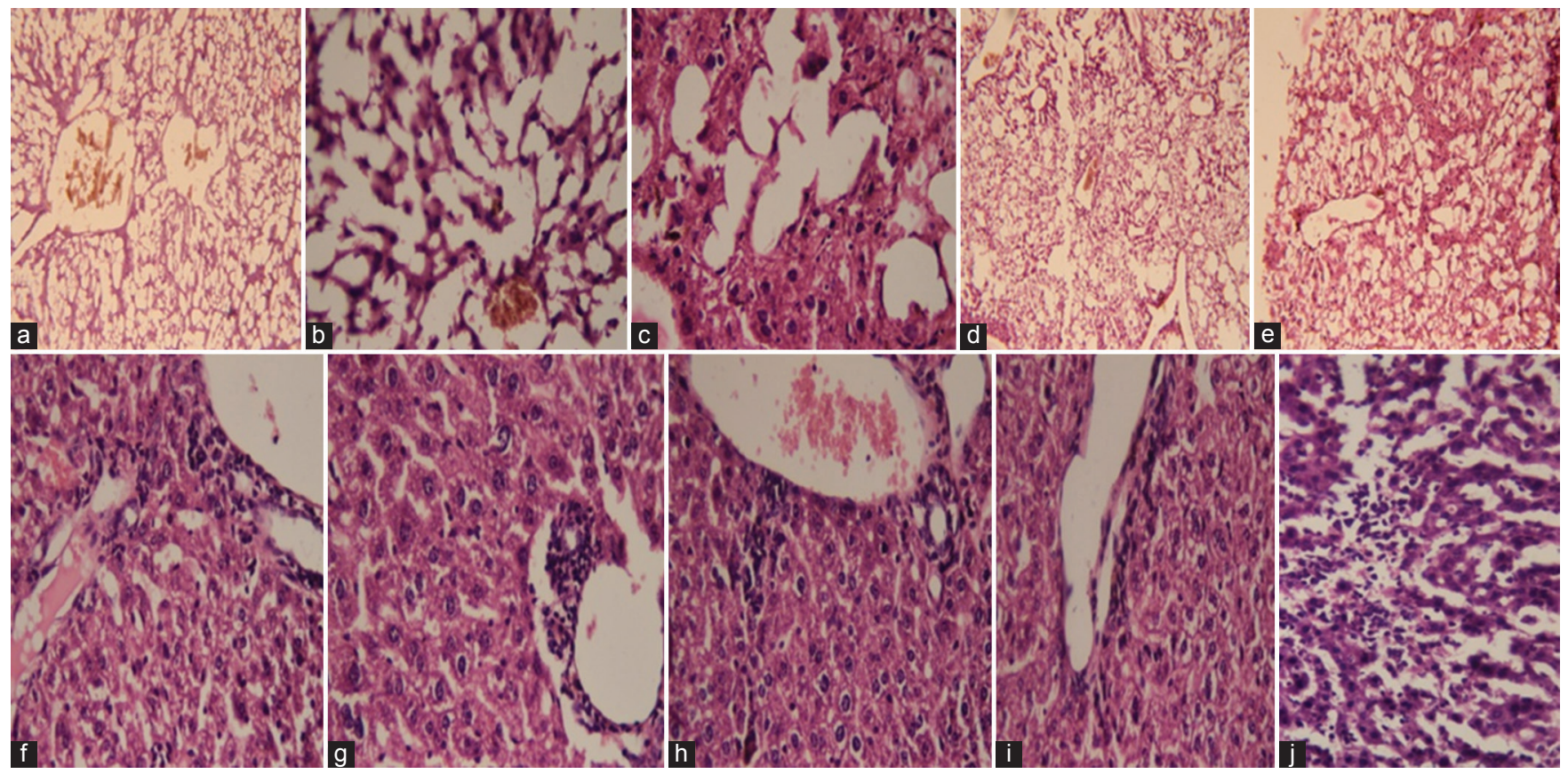

Plate 1: (a) Normal saline, (b) paraffin oil, (c) silymarin, (d) TdPf, (e) Tdpf+Dalton's lymphoma ascites (DLA), (f), paraffin oil, (g) silymarin, (h) Tdpf, (i) Tdpf+DLA, (j) DLA

effect [17]. Santhi et al., [18] reported that Cynodon dactylon leaf protein increases the level of vitamin A in ELA induced mice. Parks and Traber [19] reported that vitamin $\mathrm{E}$ is one of the most important free radical scavenging chain breaking antioxidant within the biomembrane. A significant increased level of vitamin $\mathrm{A}$ and $\mathrm{E}$ in the liver and kidney of rats induced with ammonium metavanadate toxicity by the prior treatment with green tea was reported by Soussi et al. [20]. The GSH is a powerful nucleophile, critical for cellular protection nucleophile, critical for cellular protection such as detoxification from reactive oxygen species, conjugation and excretion of toxic molecules, and control of the inflammatory cytokine cascade [21]. Bigoniya and Rana [22] reported that saponin fraction of Euphorbia neriifolia has increased the levels of hepatic $\mathrm{GSH}$ in $\mathrm{CCl}_{4}$ induced hepatotoxicity in rats.

\section{CONCLUSION}

This study was conducted to evaluate the antitumor activity of TdPf offered protective effect against DLA tumor by their in vivo antioxidant and antitumorigenic potential. The extract treatment at the dose of $52 \mu \mathrm{g} / \mathrm{kg}$ inhibited the tumor activity by the serum biochemical 
assessment. The extract also restored the hepatic lipid peroxidation and free radical scavenging enzyme GSH as well as other antioxidant enzymes such as SOD, CAT, and GPx in tumor-bearing mice to near normal levels. Our results suggest that whole plant extracts are promising anticancer reagents.

\section{ACKNOWLEDGMENTS}

The authors wish to gratefully acknowledge for their generous support of this research work to carry out.

\section{REFERENCES}

1. Hartwell JL. Plants used against cancer. A survey. Lloydia 1971;34(1):103-60.

2. Cassileth BR, Vickers AJ. High prevalence of complementary and alternative medicine use among cancer patients: Implications for research and clinical care. J Clin Oncol 2005;23(12):2590-2.

3. Lin SM, Campa MJ, Wang MZ, Howard B, Fitzgerald MC, Patz EF Jr Use of mixture models in MALDI-TOF proteomic data for peak registration. In: Proceedings of the CBGI, 2003.

4. Connors T. Anticancer drug development: The way forward. Oncologist 1996;1(3):180-181.

5. Caponigro F, Basile M, de Rosa V, Normanno N. New drugs in cancer therapy, National Tumor Institute, Naples, 17-18 June 2004. Anticancer Drugs 2005;16(2):211-21.

6. Mir MA, Sawhney SS, Jassal MM. Qualitative and quantitative analysis of phytochemicals of Taraxacum officinale. Wudpecker J Pham Phamacol 2013;2(1):1-5.

7. Tiwari P, Kumar B, Kaur M, Kaur G, Kaur H. Phytochemical screening and extraction: A review. Int Pharm Sci 2011;1(1):98-106.

8. Ghani A. Medicinal Plants of Bangladesh. $2^{\text {nd }}$ ed., Vol. 7. Dhaka: The Asiatic Society of Bangladesh; 2003. p. 176-7.

9. Kumar A, Kant S, Singh SM. Novel molecular mechanisms of antitumor action of dichloroacetate against $\mathrm{T}$ cell lymphoma: Implication of altered glucose metabolism, $\mathrm{pH}$ homeostasis and cell survival regulation. Chem Biol Interact 2012;199:29-37.

10. Rajkapoor B, Jayakar B, Murugesh N. Antitumour activity of
Bauhinia variegata on Dalton's ascitic lymphoma. J Ethnopharmacol 2003;89(1):107-9.

11. Kavitha K, Manoharan S. Anticarcinogenic and antilipid peroxidative effects of Tephrosia purpurea (Linn.) Pers in 7, 12-dimethyl benz (a) anthracene (DMBA) induced hamster buccal pouch carcinoma. Indian J Pharmacol 2006;38(3):185-9.

12. Subapriya R, Kumaraguruparan R, Ramachandran CR, Nagini S Oxidant-antioxidant status in patients with oral squamous cell carcinomas at different intraoral sites. Clin Biochem 2002;35(6):489-93.

13. Drotman RB, Lawhorn GT. Serum enzymes as indicators of chemically induced liver damage. Drug Chem Toxicol 1978;1(2):163-71.

14. Heba E, Din EL, Abeer Y, Khedr M, Mahran Z. Hepatoprotective activity ad antioxidant effects of El nabka (Zizyphus spina-christi) fruits on rats hepatotoxicity induced by carbon tetrachloride. Nat Sci 2011;9(2):1-7.

15. Santhi R, Annapoorani S. Antioxidative role of Terminalia catappa leaf protein against ELA induced mice. Int J Drug Dev Res 2009;1:81-3.

16. Nalini G, Prabu VV, Chidambaranathan N, Jeyasundari K. Evalution of antitumor activity of Cissus quadrangularis Linn against Dalton's ascetic lymphoma and Ehrlich ascites induced carcinoma in mice. Int J Pharm Sci Rev Res 2011;8(1):75-9.

17. Wang I, Gao XD, Zhou GC, Cai L, Yao WB. In vitro and in vivo antioxidant activity of aqueous extract from Choerospondias axillaries fruit. Food Chem 2008;106(3):888-95.

18. Santhi R, Annapoorani S. Efficacy of Cynodon dactylon for immunomodulatory activity. Drug Invent Today 2010;2(2):112-4.

19. Parks E, Traber MG. Mechanisms of vitamin E regulation: Research over the past decade and focus on the future. Antioxid Redox Signal 2000;2(3):405-12.

20. Soussi A, Croute F, Soleilhavoup JP, Kammoun A, El-Feki A. Impact of green tea on oxidative stress induced by ammonium metavanadate exposure in male rats. C R Biol 2006;329(10):775-84.

21. Brown LA, Harris FL, Ping XD, Gauthier TW. Chronic ethano ingestion and the risk of acute lung injury: A role for glutathione availability? Alcohol 2004;33(3):191-7.

22. Bigoniya P, Rana AC. Protective effect of Euphorbia neriifolia saponin fraction on $\mathrm{CCl}_{4}$ induced acute hepatotoxicity. Afr J Biotech 2010;9(42):7148-56. 